\title{
The effect of thermal treatment on the stress state and evolving microstructure of $\mathrm{Cu} / \mathrm{W}$ nano-multilayers
}

\author{
C. Cancellieri, ${ }^{\text {a) }}$ F. Moszner, M. Chiodi, S. Yoon, J. Janczak-Rusch, and L. P. H. Jeurgens ${ }^{\text {b) }}$ \\ Empa, Swiss Federal Laboratories for Materials Science and Technology, Laboratory for Joining \\ Technologies and Corrosion, Überlandstrasse 129, 8600 Dübendorf, Switzerland
}

(Received 13 July 2016; accepted 5 November 2016; published online 18 November 2016)

\begin{abstract}
The functionality and reliability of nano-multilayered devices and components are largely affected by the stress evolution during fabrication, processing, and operation. The impact of thermal treatment on the stress state and evolving microstructure of $\mathrm{Cu} / \mathrm{W}$ nano-multilayers, as deposited on different substrates (i.e., $\mathrm{Si}(001), \mathrm{Al}_{2} \mathrm{O}_{3}-\mathrm{C}$, and $\mathrm{Al}_{2} \mathrm{O}_{3}-\mathrm{R}$ ) by magnetron sputtering, was investigated by in-situ high temperature X-ray diffraction and high-resolution scanning electron microcopy. The as-deposited $\mathrm{Cu}$ and $\mathrm{W}$ nanolayers exhibit an out-of-plane orientation relationship according to $\mathrm{Cu}$ $\langle 111\rangle \| \mathrm{W}\langle 110\rangle$. On the $\mathrm{Al}_{2} \mathrm{O}_{3}-\mathrm{C}$ and $\mathrm{Al}_{2} \mathrm{O}_{3}-\mathrm{R}$ substrates, the $\mathrm{Cu} / \mathrm{W}$ nanomultilayers also develop a pronounced in-plane texture given by $\mathrm{Cu}\{111\}\langle 10 \overline{1}\rangle|| \mathrm{W}\{110\}\langle 00 \overline{1}\rangle$. The stress state of the $\mathrm{Cu}$ nanolayers in the as-deposited state and upon heating, investigated ex-situ, is largely imposed by the accumulated stresses in the much stiffer W nanolayers. In the as-deposited state, the W nanolayers exhibit a much larger in-plane compressive stress than the $\mathrm{Cu}$ nanolayers (i.e., -3.5 GPa versus $-1.5 \mathrm{GPa}$ ), which both mainly originate from growth stresses generated during the deposition process. The growth stresses in the as-deposited $\mathrm{Cu}$ nanolayers are relaxed after annealing at $500{ }^{\circ} \mathrm{C}$. Relief of compressive stresses in the $\mathrm{W}$ nanolayers is accompanied by grain coarsening which only occurs upon degradation of the nano-multilayered structure. The degradation of the periodic layer structure proceeds in the range of $750-900{ }^{\circ} \mathrm{C}$ and is independent of the substrate. Published by AIP Publishing. [http://dx.doi.org/10.1063/1.4967992]
\end{abstract}

\section{INTRODUCTION}

Multilayered architectures, which comprise a periodic alternation of different single- or multiple-elemental layers, are a versatile and promising route to tailor the properties and/or durability of functional materials in various application areas, such as those related to optical, magnetic, and electronic devices, tribology, and mechanical engineering. ${ }^{1}$ If the thicknesses of the alternating layers are reduced to the nano-scale, the resulting properties will be governed not only by the combined properties of the individual layers constituents but in particular, also by the structural, physical, and chemical characteristics of the internal interfaces, which include both phase and grain boundaries. ${ }^{2}$ The combination of nano-confinement and interfacial effects in such nanomultilayered (NML) systems may be exploited to optimize specific material properties, such as mechanical strength, reflectivity, pre-melting or superheating behavior, or corrosion resistance. ${ }^{3}$ However, NML architectures are intrinsically thermodynamically unstable and typically exhibit large residual stresses, which may deteriorate their long-term stability under harsh operation conditions (e.g., elevated temperatures, complex loading conditions). ${ }^{4}$

NML architectures can be straightforwardly synthesized by Physical Vapor Deposition (PVD) techniques with precise control of, e.g., individual layer thicknesses, modulation periodicity, and chemical composition. The PVD process parameters constitute a "palette for the materials scientist" to

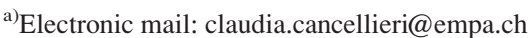

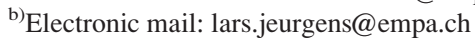

tailor the materials properties down to the nanometer scale. ${ }^{5,6}$ Magnetron-Sputtering (MS) is one of the most common non-equilibrium PVD growth methods. The MS parameters, such as target power, pressure, and substrate bias, can be effectively varied to tailor the microstructure (i.e., layer morphology, interface structure, defect density, growth stresses) and thereby the functional properties. ${ }^{7}$ For most applications (optoelectronics, magnetism, etc.), it is highly desirable to design NMLs with atomically sharp interfaces and limited residual growth stresses to ensure device reliability. However, in specific cases, the stress state in MS layers can also be exploited, for example, to induce the preferred magnetization direction, ${ }^{8}$ or in the case of epitaxial stress, to adjust the bandgap of semiconductors. ${ }^{9}$ Elastic anomalies in NMLs are generally correlated with the extreme strain states of the layer constituents due to interfacial stress. ${ }^{7,10} \mathrm{NML}-$ based devices and components, which are subjected to thermomechanical loading during processing and/or service, require an in-depth understanding of the evolution of thermal stresses and microstructural transformations during heating to ensure their long-term durability. Depending on the as-deposited microstructure, complex stress gradients with localized intensity maxima at the internal interfaces may arise during heating. ${ }^{11}$

$\mathrm{Cu} / \mathrm{W}$ nano-composites and NMLs have received increasing interest in the last decade. ${ }^{12-14}$ The high thermal conductivity of $\mathrm{Cu}$ and the low thermal expansion coefficient of $\mathrm{W}$ make $\mathrm{Cu}-\mathrm{W}$ composites attractive for thermal management applications. The $\mathrm{Cu}-\mathrm{W}$ system is highly immiscible due to the different crystal structures of $\mathrm{Cu}$ and $\mathrm{W}$ (fcc vs. bcc), their lattice parameter mismatch (15\% difference), and 
their positive mixing enthalpy $(+36 \mathrm{~kJ}) .{ }^{15}$ Hardness and mechanical properties of $\mathrm{Cu} / \mathrm{W}$ NMLs were found to be dependent on the multilayer period. Thermal treatment of $\mathrm{Cu} / \mathrm{W}$ architectures above $200^{\circ} \mathrm{C}$ results in a drastic reduction of the hardness. ${ }^{14}$ The breaking of the NML periodic structure at high temperature has been investigated by means of Scanning Electron Microscopy (SEM) and X-ray diffraction (XRD). ${ }^{16}$ The thermal degradation of the Cu/W NML's structure into a nanocomposite structure was found to be rate-determined by $\mathrm{W}$ diffusion along internal interfaces (i.e., grain- and phase-boundaries). However, the role of intrinsic (growth) and thermally induced stresses in the NML degradation upon heating is not yet clarified. Elastic properties of $\mathrm{W}$ in $\mathrm{Cu} / \mathrm{W}$ multilayers have been investigated in the past, ${ }^{17}$ finding unusually high values for the stress tensor. The high compressive stress state in $\mathrm{W}$ was attributed to an interfacial effect. ${ }^{18}$ For $\mathrm{Cu} / \mathrm{W}$ multilayers, the level of growth stress in the constituent layers (i.e., in the asdeposited state) can be very different. The in-plane stress in the $\mathrm{W}$ layers is always highly compressive (up to $-5 \mathrm{GPa}$ ), independently of the thickness and layer period. ${ }^{12,17,19}$ On the contrary, the alternating $\mathrm{Cu}$ layers were seen to exhibit different stress states in the range from -0.5 to $+2.8 \mathrm{GPa}$ (i.e., from compressive to highly tensile), depending on the thickness and on the deposition conditions. ${ }^{20}$ Notably, the substrate can also influence the stress state of the multilayer. A systematic and comprehensive study on the impact of thermal treatments on the internal stress state and evolving microstructure in $\mathrm{Cu} / \mathrm{W}$ NML on different substrates is still missing, but of fundamental and technological interest. Most importantly, not only the average stress state in the $\mathrm{Cu} / \mathrm{W}$ NML but also the stress levels in the individual $\mathrm{Cu}$ and $\mathrm{W}$ nanolayers should be monitored as a function of the heating temperature. XRD provides a powerful method to independently determine both the microstructural characteristics (e.g., phase constitution, texture, and grain size) and the residual stress states of each multilayer constituent independently (in our case $\mathrm{Cu}$ and $\mathrm{W}$ ). In the following, the microstructure of $\mathrm{Cu} / \mathrm{W}$ NMLs as deposited on different substrates by MS is accessed by in-situ high temperature XRD (HT-XRD) and high resolution SEM (in planar and cross sectional view). Moreover, the change in the stress state and the structure imposed during heat treatment from room temperature (RT) up to $900{ }^{\circ} \mathrm{C}$ is revealed.

\section{EXPERIMENTAL METHODS}

\section{A. Sample preparation}

$\mathrm{Cu} / \mathrm{W}$ NMLs were deposited on 2 in. epi-polished $\alpha$ $\mathrm{Al}_{2} \mathrm{O}_{3}$ and $\mathrm{Si}$ single-crystalline substrates (sapphire- $\mathrm{R}$ (11 102 ), sapphire-C (0001), and $\mathrm{Si}(001)+15 \mathrm{~nm}$ of $\mathrm{Si}_{3} \mathrm{~N}_{4}$ wafers, see Table I) by DC unbalanced magnetron sputtering in a high vacuum chamber (base pressure $<10^{-8}$ mbar) from two 2 in. targets of pure $\mathrm{W}(99.95 \%)$ and $\mathrm{Cu}(99.99 \%)$ confocally arranged and operated at $200 \mathrm{~W}$. The insertion of the $\mathrm{Si}_{3} \mathrm{~N}_{4}$ layer before $\mathrm{W}$ deposition prevents the formation of tungsten silicide observed when $\mathrm{W}$ is grown directly on the Si substrate. ${ }^{21}$ Before insertion in the deposition apparatus, the sapphire substrates were ultrasonically cleaned using acetone and
TABLE I. Substrates and layers orientations (in NML) and thermal coefficients. $^{22,23}$

\begin{tabular}{lcc}
\hline \hline Material & Bulk thermal coefficients $\left(10^{-6} / \mathrm{K}\right)$ & Orientation \\
\hline $\mathrm{Al}_{2} \mathrm{O}_{3}-\mathrm{R}$ substrate & 8 & $(1102)$ \\
$\mathrm{Al}_{2} \mathrm{O}_{3}-\mathrm{C}$ substrate & 8 & $(0001)$ \\
$\mathrm{Si}$ substrate & 2.49 & $(001)$ \\
$\mathrm{Cu}$ & 16.5 & $(111)$ \\
$\mathrm{W}$ & 4.3 & $(110)$ \\
\hline
\end{tabular}

ethanol. Prior to deposition, possible surface contaminant on the $\alpha-\mathrm{Al}_{2} \mathrm{O}_{3}$ substrates (mostly adventitious carbon) was removed by $\mathrm{Ar}^{+}$sputter cleaning for 5 min applying a RF bias of $100 \mathrm{~V}$. First, a $25 \mathrm{~nm}$-thick $\mathrm{W}$ buffer layer was deposited on the sputter-cleaned substrate. Next, 100 repetitions of alternating $\mathrm{Cu}$ and $\mathrm{W}$ layers with an individual (nominal) thickness of $5 \mathrm{~nm}$ were deposited on top. For the stress measurements, the as-prepared samples were isothermically annealed ex-situ at different temperatures $(400,500,600,650,700,750$, and $\left.800^{\circ} \mathrm{C}\right)$ for $100 \mathrm{~min}$ in a vacuum $\left(<10^{-5} \mathrm{mbar}\right)$.

\section{B. XRD}

The Bruker D8 Discover X-ray diffractometer, operated in

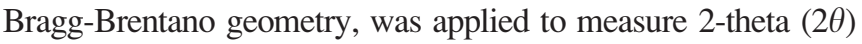
scans and stress state for the as-deposited and annealed samples. To access the texture, pole figures of $\mathrm{Cu}\langle 111\rangle$ and $\mathrm{W}\langle 110\rangle$ family of planes were recorded on samples grown on different substrates. Stress and texture measurements were recorded at RT on $e x$-situ annealed samples. HT-XRD experiments were performed with a PANalytical X'Pert PRO MPD X-ray diffractometer with a gas-tight Anton Paar XRK-900 heating chamber equipped for heating and gas feeding (5850 TR, Brooks instrument), applying a $\mathrm{H}_{2} / \mathrm{N}_{2}(\mathrm{~g})$ gas mixture of 5 vol. $\% \mathrm{H}_{2}$ (99.999\%, Messer) in $\mathrm{N}_{2}(99.999 \%$, Messer) at a flow rate of $100 \mathrm{ml} / \mathrm{min}$. Diffraction patterns ( $2 \theta$ range of $10^{\circ}-90^{\circ}$ step size of $0.026^{\circ}$; using $\mathrm{Cu} \mathrm{K} \alpha_{1,2}$ radiation, at $40 \mathrm{kV}$ and $40 \mathrm{~mA}$ ) were recorded during heating and cooling (from RT to $900{ }^{\circ} \mathrm{C}$ and back). To enhance the surface sensitivity (i.e., to increase the signal contribution from the top layers of the NML), separate Grazing Incidence XRD (GI-XRD) measurements were performed applying the same thermal ramp, while fixing the incidence angle at $10^{\circ}$ and recording the entire diffractograms from $20^{\circ}-80^{\circ}$. For more details on the measurement geometries of the XRD experiments, see supplementary material.

\section{SEM analysis}

High-resolution SEM analysis was performed in plain and in cross sectional views using a Hitachi S-4800 instrument equipped with a Bruker XFlash $6 \mid 60$ energy dispersive $\mathrm{X}$-ray (EDX) detector. Cross-sectional cuts were prepared by using a Hitachi IM4000 Ar ion milling system applying an acceleration voltage of $6 \mathrm{kV}$, a discharge voltage of $1.5 \mathrm{kV}$, and a swing angle of $\pm 30^{\circ}$.

\section{Residual stress analysis}

The most common XRD method for stress-analysis is the so-called $\sin ^{2} \psi$ method, ${ }^{24}$ which is based on the 
variation of the diffraction peak position with $\sin ^{2} \psi, \psi$ being the angle between the normal to the diffracting planes and the surface normal (see supplementary material). However, for highly textured materials (as is the case for the studied NMLs), the so-called Crystallite-Group Method (CGM) is more appropriate. ${ }^{25}$ The CGM is a special case of the $\sin ^{2} \psi$ technique. It differs mainly in the fact that it explicitly takes into account the texture of the sample, rather than using $\mathrm{X}$-ray elastic constants to account for the geometrical distribution of the crystallites. It also assumes that on average every crystallite (having the same orientation) is exposed to the same stress. Elastic analysis via Hookes law relates the strain to the stress tensor (and vice versa) through stiffness or compliance tensors. ${ }^{26,27}$ In the case of textured films, it is assumed that all crystallites having the same orientation form a unique crystal. This implies that every crystallite shows the same stress state (Reuss averaging scheme). Due to its specific geometry, a thin film deposited onto a substrate is free to expand or contract along the film normal direction. Thus, the stress in this direction and shear components that involve the normal direction are equal to zero $\left(\sigma_{33}=\sigma_{13}\right.$ $=\sigma_{23}=0$ ). Moreover, an equal-biaxial stress state is often observed $\left(\sigma=\sigma_{11}=\sigma_{22}\right)$, consequently all in-plane shear components are also zero. Hence, uniaxial stress and rotational symmetry have been assumed for the $\mathrm{Cu}$ layers and the $\{111\}\langle 2 \overline{1} 1\rangle$ CGM was used to determine the stress. The $\mathrm{W}$ interlayers contain a distinct polycrystalline component (besides the textured component; see Sec. III) and therefore both methods have been applied to determine the respective stress state: i.e., the $\sin ^{2} \psi$ analysis was performed on the basis of the (211) reflection, where the CGM was performed on the basis of the $\{110\}\langle\overline{1} 12\rangle$ group of reflections. The stress values for $\mathrm{W}$, as presented in Sec. III, refer to the CGM only, although similar values (within the error bars) have been found with the $\sin ^{2} \psi$ method, see supplementary material for details. This result is indeed expected for $\alpha-\mathrm{W}$ because it is elastically isotropic.

\section{RESULTS AND DISCUSSION}

\section{A. XRD analysis of the as-deposited Cu/W NMLs}

The $\mathrm{W}\{110\}$ and $\mathrm{Cu}\{111\}$ pole figures, as measured from the $\mathrm{Cu} / \mathrm{W}$ NMLs deposited on the $\mathrm{Al}_{2} \mathrm{O}_{3}-\mathrm{C}$, $-\mathrm{R}$ and $\mathrm{Si}(001) /\left[\mathrm{Si}_{3} \mathrm{~N}_{5}\right]_{15 \mathrm{~nm}}$ substrates, are given in Fig. 1 . The common central peak at $\psi=0^{\circ}$ corresponds to the preferential growth direction of [111] for $\mathrm{Cu}$ and [110] for W. For all three substrates, a ring of maximum intensity occurs at $\psi=60^{\circ}$ for $\mathrm{W}$ (corresponding to the angles between the

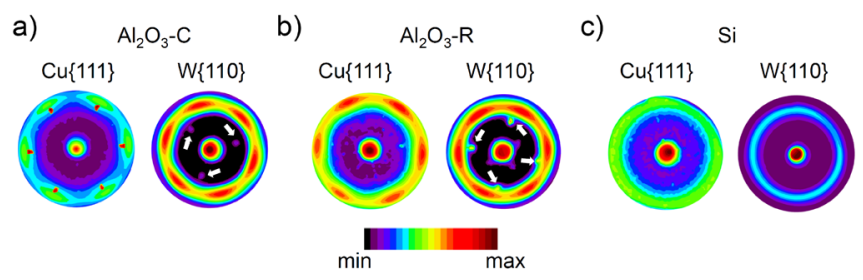

FIG. 1. Pole figures of $\mathrm{W}\{110\}$ and $\mathrm{Cu}\{111\}$ on (a) $\mathrm{Al}_{2} \mathrm{O}_{3}-\mathrm{C}$, (b) $\mathrm{Al}_{2} \mathrm{O}_{3}-\mathrm{R}$, and (c) $\mathrm{Si}$ substrates. The white arrows indicate the second $\mathrm{W}\langle 111\rangle$ and $\mathrm{W}\langle 100\rangle$ orientations present in $\mathrm{Al}_{2} \mathrm{O}_{3}-\mathrm{C}$ and $-\mathrm{R}$ substrates, respectively.
$\mathrm{W}(110)$ and $\mathrm{W}(011)$ planes) and at $\psi=70.53^{\circ}$ for $\mathrm{Cu}$ (corresponding to the angles between for the $\mathrm{Cu}(111)$ and $\mathrm{Cu}(11 \overline{1}))$. This implies that all the NMLs exhibit the same out-of-plane orientation relationship according to $\mathrm{Cu}\{111\} \|$ $\mathrm{W}\{110\}$ independently of the type of substrate. This is expected, since the $\mathrm{Cu}\{111\}$ and $\mathrm{W}\{110\}$ planes constitute the most densely packed planes of lowest surface energy. For the NMLs deposited on sapphire substrates (-C and $-\mathrm{R})$, the intensity rings at $\psi=60^{\circ}$ for $\mathrm{W}$ and $\psi=70.53^{\circ}$ for $\mathrm{Cu}$ exhibit 6 high intensity poles: see Figs. 1(a) and 1(b), respectively. This denotes a coherent interface between $\mathrm{Cu}$ and $\mathrm{W}$ with a crystallographic orientation relationship according to: $\mathrm{Cu}\{111\}\langle 10 \overline{1}\rangle|| \mathrm{W}\{110\}\langle 00 \overline{1}\rangle$. Moreover, 3 additional poles at $\psi \sim 35.3^{\circ}$ and 4 poles at $\psi \sim 45^{\circ}$ are clearly distinguishable in Figs. 1(a) and 1(b), respectively, as indicated with white arrows. This weaker, second texture component arises from the epitaxial relationship of the first $25 \mathrm{~nm}$ thick $\mathrm{W}$ layer in contact with the single-crystalline $\mathrm{Al}_{2} \mathrm{O}_{3}$ substrate. Consequently, the $\mathrm{W}$ buffer layer does not develop a $\{110\}$ out-of-plane texture, like the subsequently deposited $\mathrm{W}$ nanolayers on $\mathrm{Cu}$. The $\mathrm{W}$ layer directly in contact with the substrate presents a $\{111\}$ out-of-plane texture on the 6-fold symmetric $\mathrm{Al}_{2} \mathrm{O}_{3}-\mathrm{C}$ surface and a $\{100\}$ out-of-plane texture on 4-fold symmetric $\mathrm{Al}_{2} \mathrm{O}_{3}$ - $\mathrm{R}$ surface. ${ }^{28,29}$ Subsequent growth of $\mathrm{Cu}$ and $\mathrm{W}$ nanolayers on the first epitaxial $\mathrm{W}$ buffer layer then proceeds along the preferred directions of [111] for $\mathrm{Cu}$ and [110] for $\mathrm{W}$ (corresponding to the most densely packed planes of lowest surface energy) and results in the same inplane texture of the $\mathrm{Cu} / \mathrm{W}$ NML on $\mathrm{Al}_{2} \mathrm{O}_{3}-\mathrm{C}$ and $\mathrm{Al}_{2} \mathrm{O}_{3}-\mathrm{R}$ (see above). The $\mathrm{Si}(001)$ substrate is covered with an (predominantly) amorphous $\mathrm{Si}_{3} \mathrm{~N}_{4}$ buffer layer, which hinders the formation of a preferred crystallographic orientation relationship between the single-crystalline substrate and the $25 \mathrm{~nm}$-thick W bottom layer during growth. Consequently, the subsequent $\mathrm{W}$ and $\mathrm{Cu}$ layers do not inherit a distinct in-plane texture during growth, resulting in a fiber-texture or random in-plane orientation. ${ }^{13}$

\section{B. Microstructure of the as-deposited and heat-treated Cu/W NMLs by SEM}

SEM micrographs of the as-deposited and heat-treated NML are shown in Fig. 2, both in plain and cross-sectional views. The surface of the as-deposited NMLs is very uniform and exhibits a grain-like morphology (as originating from the waviness of the deposited nanolayers; see Ref. 16) with no evidence of cracks, voids, and/or delaminations (Fig. 2(a)). In the cross-sectional view, the $25 \mathrm{~nm}$ thick $\mathrm{W}$ bottom layer and the periodicity of the alternating $\mathrm{Cu} / \mathrm{W}$ layers with individual (nominal) thicknesses of $5 \mathrm{~nm}$ each are clearly resolved (Fig. 2(b)). The deposited nanolayers are relatively uniform in thickness adjacent to the substrate but become less uniform in thickness (i.e., wavier) towards the surface. The surface morphology (in planar view, Fig. 2(c)) and layered structure (in cross-sectional view, Fig. 2(d)) of the $\mathrm{Cu}$ / W NML are largely changed after the temperature treatment up to $900^{\circ} \mathrm{C}$, see Figs. 2(c) and 2(d). First, the original stratified structure has completely degraded into a nanocomposite structure, consisting of globular W particles embedded in a 

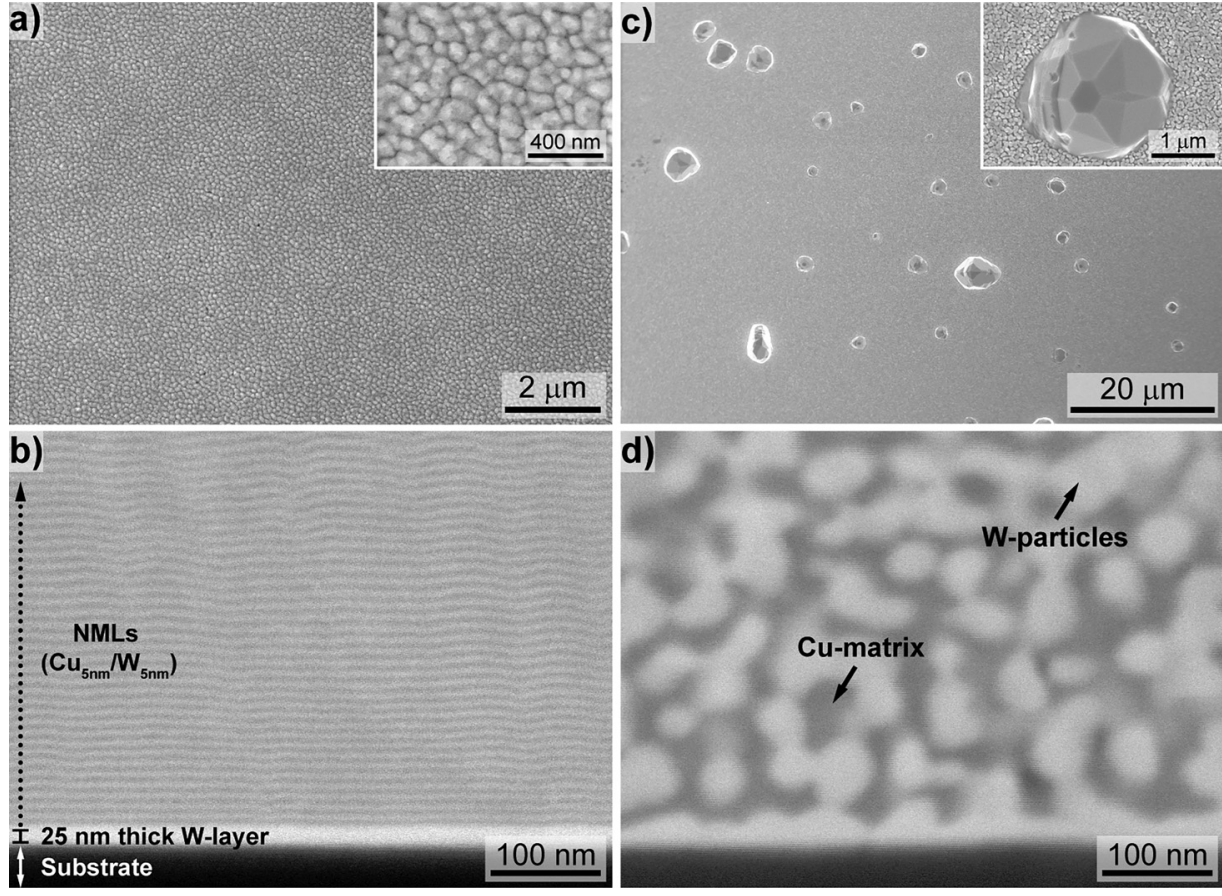

FIG. 2. Typical (a) planar and (b) crosssectional SEM images of a $\mathrm{Cu} / \mathrm{W}$ multilayer in the as deposited state. (c) Planar and (d) cross-sectional SEM images of similar sample after HT-XRD (after $900^{\circ} \mathrm{C}$ thermal ramp). In the insets in (a) is shown a magnified section of the top most surface. The inset in (b) is a magnified section of a facetted particle.
$\mathrm{Cu}$ matrix (Fig. 2(d)). Second, the originally smooth NML surface has been partially covered by facetted protrusions. EDX analysis (not shown here) revealed that the individual surface protrusions mainly consist of $\mathrm{Cu}$, in accord with Ref. 16. The outward migration of $\mathrm{Cu}$ from the NML interior to the outer surface, forming facetted nanocrystallites, is attributed to a stress-assisted driving mechanism, as discussed in the following.

\section{HT-XRD analysis of the Cu/W NMLs during heating}

The measured $2 \theta$-scans in the selected range from $30^{\circ}$ to $48^{\circ}$, as recorded from the NMLs during heating up to $900^{\circ} \mathrm{C}$ and during subsequent cooling to RT, are shown in Fig. 3. The intensity modulation in the XRD pattern, also indicated as satellite peaks, is characteristic for periodic layer structures as multilayers. ${ }^{30}$ The satellite peaks are compatible with calculated diffractograms of a superlattice exhibiting $\mathrm{Cu}\{111\}$ and $\mathrm{W}\{110\}$ textures: see Ref. 16 for details. The evolution of the satellite peaks as a function of temperature is displayed in Fig. 3. Despite the different textures of the first $\mathrm{W}$ buffer layer and the subsequently deposited $\mathrm{Cu} / \mathrm{W}$ NML sequence, the diffracted intensity modulation (typical of an ordered periodic structure in the as-deposited state) vanishes completely during heating in the temperature range between 750 and $900^{\circ} \mathrm{C}$, independently of the parent substrate (see Fig. 3).

This is indeed an unexpected and surprising result recognizing that the different substrates not only induce different textures of the deposited NML (see Sec. III A) but also possess different thermal expansion coefficients (see Table I). The thermal expansion coefficient of $\mathrm{Al}_{2} \mathrm{O}_{3}$ is almost a factor of 3 larger than that of Si. Nevertheless, NML degradation takes place in the same temperature range for all studied substrates, which suggests that the degradation of the NML structure upon annealing is not governed by thermally induced stresses due to the thermal expansion mismatch between the substrate and the NML; i.e., other mechanisms such as internal stresses should be called into play. a)

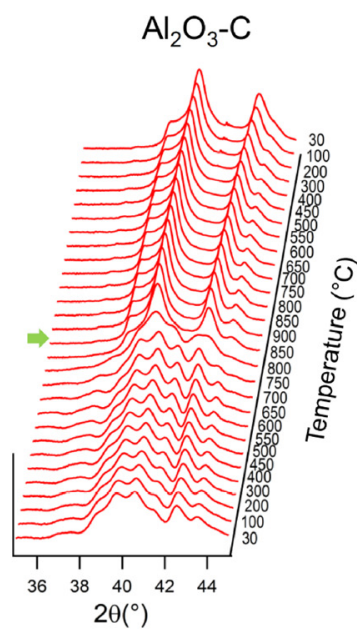

b)

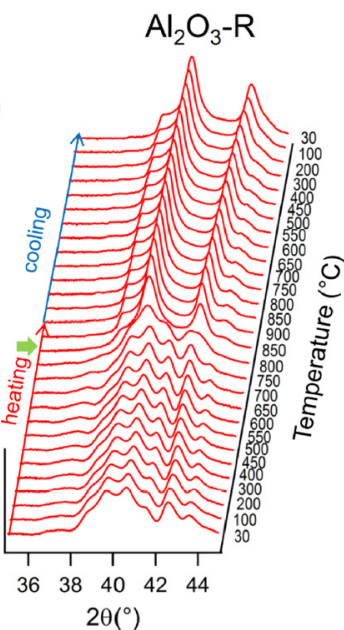

c)

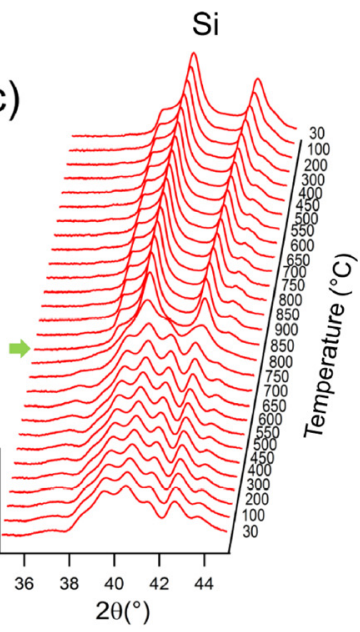

FIG. 3. HT-XRD measurements on (a) $\mathrm{Al}_{2} \mathrm{O}_{3}-\mathrm{C}$, (b) $\mathrm{Al}_{2} \mathrm{O}_{3}-\mathrm{R}$, and (c) Si substrates. The arrows indicate the temperatures where the degradation of the multilayer structure occurs. 


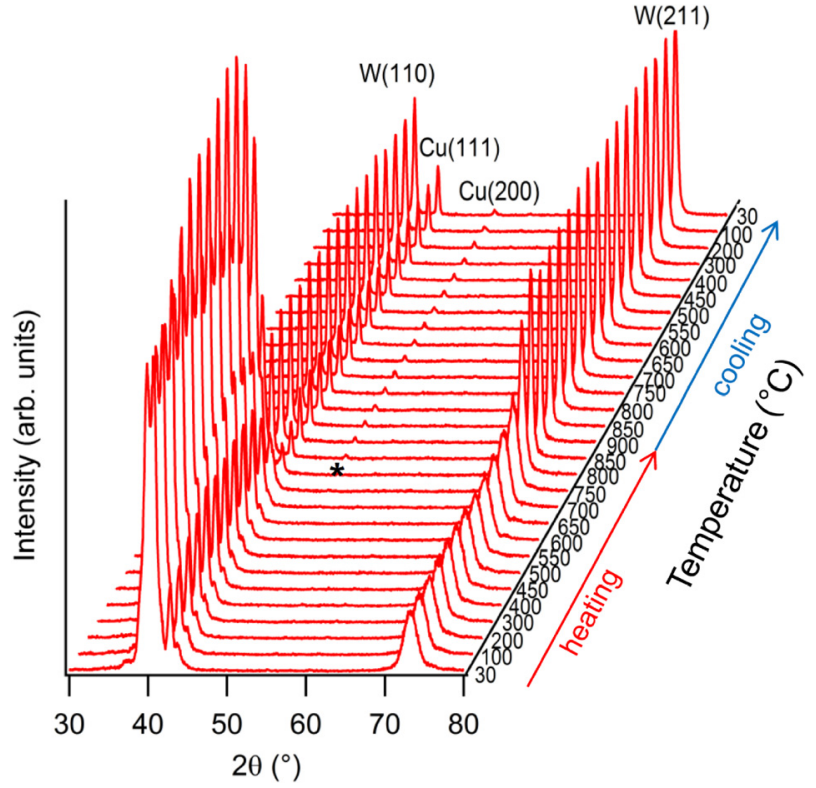

FIG. 4. In-situ high temperature GI-XRD pattern of $\mathrm{Cu} / \mathrm{W}$ multilayers. The temperatures are indicated on the right axis. The peak of $\mathrm{Cu}$ (200) appears at a temperature of $\sim 750^{\circ} \mathrm{C}$ indicated with a star $(*)$.

Various possible explanations for multilayer degradation occurring at elevated temperatures have been proposed. ${ }^{31}$ For immiscible systems like $\mathrm{Cu}$ and $\mathrm{W}$, capillary forces can drive layer recession to reduce the (excess) Gibbs energies associated with internal interfaces (i.e., phase and grain boundaries). Thermal grooving of grain boundaries initiates layer pinch-off when the upper and lower grooves of the same grain boundary merge. In Ref. 16, the pinching of the $\mathrm{W}$-layer by $\mathrm{Cu}$ is indeed observed. Stress effects are though to play an important role in determining such morphological instabilities of multilayers. ${ }^{32}$ In particular, the lattice misfits at incoherent and semicoherent interfaces between phase A and $\mathrm{B}$ in an $\mathrm{A} / \mathrm{B}$ NML can induce coherency stresses within the alternating nanolayers in the GPa range. Internal stresses can also have a dramatic effect on the directional coarsening of precipitates in alloys. The evolution of the residual stresses upon thermal treatment of $\mathrm{Cu}$ and $\mathrm{W}$ layers will be presented in Sec. III D.

The NMLs grown on $\mathrm{Si}$ and $\mathrm{Al}_{2} \mathrm{O}_{3}-\mathrm{R}$ substrates were also analyzed during heating and subsequent cooling by in-situ high temperature GI-XRD (see Fig. 4). The as-deposited NMLs on the $\mathrm{Al}_{2} \mathrm{O}_{3}-\mathrm{C}$ and $\mathrm{Al}_{2} \mathrm{O}_{3}-\mathrm{R}$ exhibit similar textures and therefore only the $\mathrm{Al}_{2} \mathrm{O}_{3}-\mathrm{R}$ was chosen for a comparison with $\mathrm{Si}$. The temperature range of $750-900{ }^{\circ} \mathrm{C}$ for $\mathrm{NML}$ degradation during heating is confirmed by the GI-XRD analysis. Despite the strong textures of the $\mathrm{W}$ and $\mathrm{Cu}$ layers, a weak polycrystalline component is detected in the in-situ GI diffractograms of the $\mathrm{Cu} / \mathrm{W}$ NMLs, as associated with the $\mathrm{W}(211)$ reflection. Other $\mathrm{W}$ reflections (i.e., except for $\mathrm{W}(110)$ and $\mathrm{W}(211))$ are too weak to be detected. Strikingly, the disappearance of the satellite structure coincides with the appearance of the $\mathrm{Cu}(200)$ reflection, as attributed to the outflow of confined $\mathrm{Cu}$ from the interior of the NML to the outer surface, forming $\mathrm{Cu}$ crystals with a random in-plane orientation (resulting in a polycrystalline texture): see Sec. IIC and related discussion in Ref. 16. The average grain size of $\mathrm{W}$, as estimated from the FWHM (using the Scherrer formula) of the W(211) peak, is plotted as a function of temperature in Fig. 5(a). It follows that NML degradation with $\mathrm{Cu}$ outward migration is accompanied by abrupt grain coarsening of $\mathrm{W}$ in the range of $750-900^{\circ} \mathrm{C}$. The resulting $\mathrm{W}$ grain size remains nearly constant during subsequent cooling down to RT. The relative change of the $\mathrm{W}(211)$ plane spacing $\left(\mathrm{d}_{(211)}\right)$ with respect to the bulk spacing $\left(d_{0}\right)$, i.e. $\left(d_{(211)}-d_{0}\right) / d_{0}$, is shown in Fig. 5(b). It follows that the lattice expansion does not follow an ideal thermoelastic behavior during heating; i.e., irreversible plastic deformation occurs during heating. The lattice expansion follows the expected nominal slope upon cooling from $900{ }^{\circ} \mathrm{C}$ to $\mathrm{RT}$.

\section{Stress analysis of the Cu/W NMLs after thermal treatments}

The average residual stress in the $\mathrm{Cu}$ and $\mathrm{W}$ layers on $\mathrm{Al}_{2} \mathrm{O}_{3}-\mathrm{R}$ and $\mathrm{Si}$ substrates, as determined by the CGM (see $\mathrm{Sec}$. II D), is plotted as a function of the annealing temperature in Fig. 6(a). In the as-deposited state, the $\mathrm{Cu}$ and $\mathrm{W}$ nanolayers possess a large compressive average in-plane stress of roughly $-1.5 \mathrm{GPa}$ and $-3.0 \mathrm{GPa}$, respectively, on the $\mathrm{Al}_{2} \mathrm{O}_{3}-\mathrm{R}$ substrate. On the Si substrate, similar values for the compressive stress have been found in $\mathrm{Cu}$ whereas a more pronounced compressive stress was found in $\mathrm{W}(\sim-4 \mathrm{GPa})$. W is much stiffer than $\mathrm{Cu}$ and hence the much larger compressive growth stress in the $\mathrm{W}$ nanolayers will be largely superimposed on the much softer $\mathrm{Cu}$ nanolayers. Indeed the lattice of a $\mathrm{Cu}$ monolayer in contact with $\mathrm{W}$ fully adjusts to the $\mathrm{W}$ lattice parameter. ${ }^{33-35}$ The $\mathrm{Cu}(111) / \mathrm{W}(110)$ interface between the alternating $\mathrm{W}$ and $\mathrm{Cu}$ layers (corresponding to the boundary plane between the a)

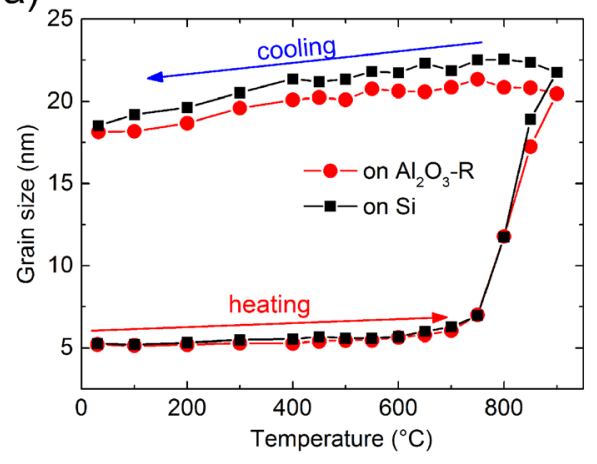

b)

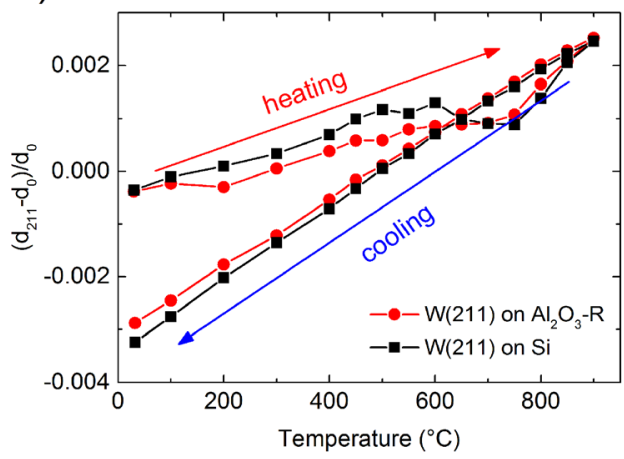

FIG. 5. In-situ (a) W grain size evolution and (b) $d_{(211)}$ expansion as a function of temperature. Investigations on $\mathrm{Si}$ and sapphire-R substrates are shown. 


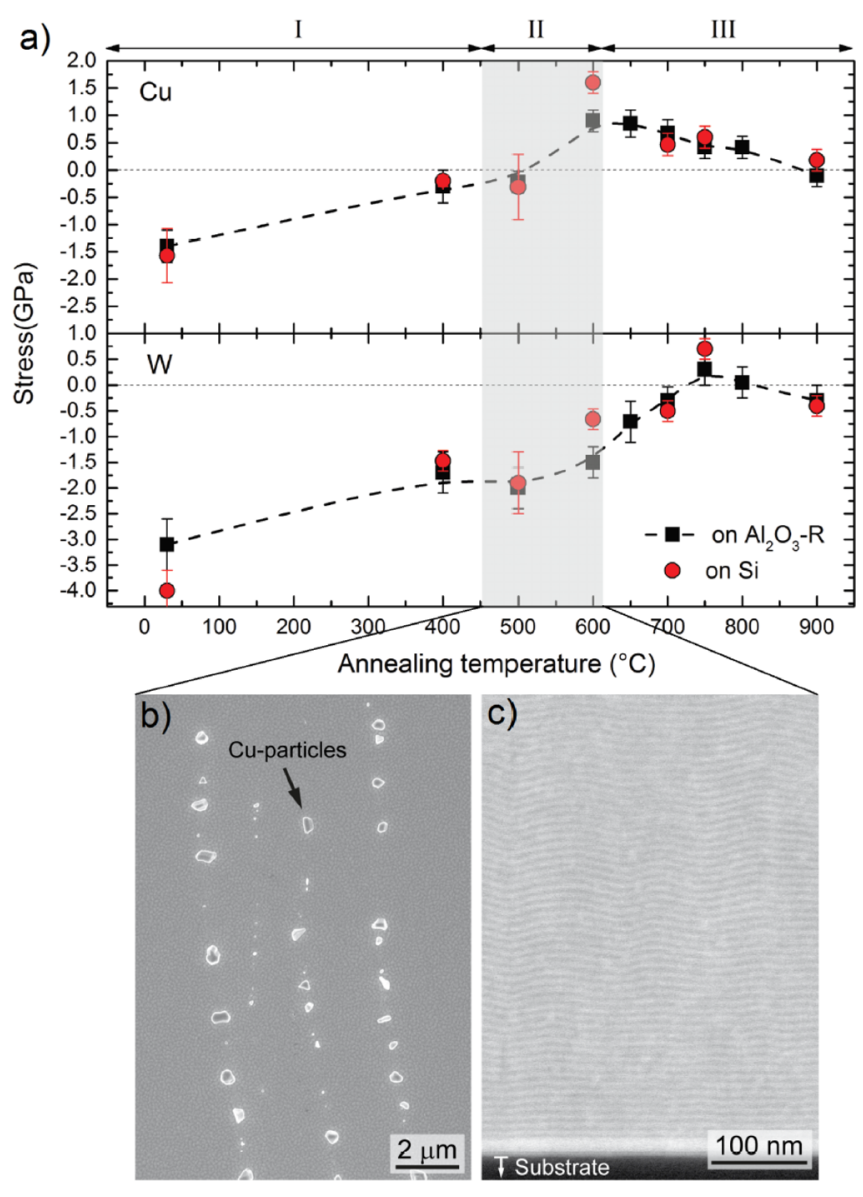

FIG. 6. (a) Residual stress analysis of $\mathrm{Cu}$ and $\mathrm{W}$ layers on an $\mathrm{Al}_{2} \mathrm{O}_{3}-\mathrm{R}$ substrate plotted as a function of the annealed temperature. The red points (circle) are the results on the same study carried out on a Si substrate. The dashed lines are guide to the eyes. Error bars are derived from the linear fit of the lattice parameter as a function of $\sin ^{2} \psi$. The shadowed region represents the temperature window where the Cu outflow is observed by SEM. In panel (b) and (c), corresponding SEM pictures for a $500^{\circ} \mathrm{C}$ annealed samples are shown in planar and cross sectional views, respectively.

most densely packed atomic planes of $\mathrm{W}$ and $\mathrm{Cu}$; see Sec. III A) also has the lowest energy and is thus thermodynamically preferred. ${ }^{33}$ In accord with the above discussion, it may be assumed that any changes in the stress state of the $\mathrm{W}$ nanolayers during growth and subsequent heating will be largely imposed to the confined $\mathrm{Cu}$ nanolayers. Indeed, as reflected in region I in Fig. 6, the course of the stress evolution upon heating is qualitatively similar for $\mathrm{Cu}$ and $\mathrm{W}$. The as-deposited $\mathrm{Cu}$ nanolayers possess an average in-plane compressive stress of $-1.5 \mathrm{GPa}$, which is fully released upon heating up to $500{ }^{\circ} \mathrm{C}$ (see the regions I and II in Fig. 6(a)). The in-plane compressive stress in the as-deposited $\mathrm{W}$ layers is significantly larger, i.e., $-3.5 \mathrm{GPa}$. It is not yet fully released upon heating up to $500^{\circ} \mathrm{C}$ and the $\mathrm{W}$ layers still possess a large compressive stress of $-2 \mathrm{GPa}$ at $500{ }^{\circ} \mathrm{C}$ (see region II in Fig. 6(a)). Here, it is emphasized that the residual stresses and the corresponding SEM pictures in Fig. 6(a) were acquired at RT, i.e., after annealing. Accordingly, a stress-free state at RT not necessarily implies a stress-free state at the respective annealing temperature. However, assuming that the $\mathrm{W}$ nanolayers superimpose their stress on $\mathrm{Cu}$ and considering the relatively small thermal mismatch between $\mathrm{W}, \mathrm{Si}$, and $\mathrm{Al}_{2} \mathrm{O}_{3}-\mathrm{R}$ (see Table I), any additional stress contribution generated during cooling (due to the thermal mismatch) should be relatively small. The marked region II from $450-600{ }^{\circ} \mathrm{C}$ in Fig. 6(a) denotes the temperature range for which the thermally activated migration of $\mathrm{Cu}$ from the NML interior to the outer surface occurs. In Fig. 6(b), the corresponding SEM analysis taken after annealing at $500{ }^{\circ} \mathrm{C}$ clearly shows the $\mathrm{Cu}$ outflow on the surface, in agreement with Ref. 16, while the multilayer periodic structure is still preserved, see Fig. 6(c). As evidenced for $\mathrm{Cu} / \mathrm{W}$ (and in other systems ${ }^{36}$ ), facetted $\mathrm{Cu}$ particles of different geometries and sizes appear on the outer surface after annealing (cfr. Fig. 2(c) and Ref. 16). The confined $\mathrm{W}$ nanolayers still possess an in-plane compressive stress state up to $600^{\circ} \mathrm{C}$. Acknowledging the higher mobility and ductility of $\mathrm{Cu}$ as compared to $\mathrm{W},{ }^{37,38}$ the resulting local stress gradients in the NML may drive $\mathrm{Cu}$ from the compressive stress regions in the interior of the NML to the stress-free surface. The stressassisted outward migration of $\mathrm{Cu}$ apparently becomes thermally activated at $500^{\circ} \mathrm{C}$ and terminates at around $600^{\circ} \mathrm{C}$ and is succeeded by a gradual breaking down of the periodic NML structure. ${ }^{16}$ As shown in Ref. 16, the gradual degradation of the $\mathrm{Cu}$ / W NMLs into a nanocomposite structure at $T>750^{\circ} \mathrm{C}$ is ratedetermined by the thermally activated diffusion of $\mathrm{W}$ along internal interfaces (i.e., grain- and phase-boundaries). As demonstrated in the present study, the gradual degradation of the NML structure at $T>750^{\circ} \mathrm{C}$ is accompanied by an enhanced relaxation of compressive stresses in the $\mathrm{W}$ nanolayers (see region III in Fig. 6). The compressive stress in $\mathrm{W}$ is fully relaxed at around $750^{\circ} \mathrm{C}$, while the $\mathrm{Cu}$ nanolayers initially develop a tensile stress state of $+1 \mathrm{GPa}$ at $600^{\circ} \mathrm{C}$ (presumably imposed by $\mathrm{W}$; see above), which gradually relaxes to zero at $900^{\circ} \mathrm{C}$. Surprisingly, the stress evolutions of $\mathrm{Cu}$ and $\mathrm{W}$ in the $\mathrm{Cu} / \mathrm{W}$ NMLs are relatively independent of the parent substrate. Small differences can be found in the absolute stress values of $\mathrm{Cu}$ and W measured on $\mathrm{Si}$ and $\mathrm{Al}_{2} \mathrm{O}_{3}-\mathrm{R}$ substrates although the overall trend with the annealing temperature is similar. In order to rationalize this puzzling result, the origin of the in-plane stress component will be investigated, in the following.

The total average stress in the multilayer, $\sigma_{T O T}$, can be deconvoluted into the so-called coherency stress $\left(\sigma_{c o h}\right)$ and substrate-interaction stress $\left(\sigma_{S I}\right)^{39,55,56}$

$$
\left\langle\sigma_{T O T}^{C u, W}\right\rangle=\left\langle\sigma_{c o h}^{C u, W}\right\rangle+\sigma_{S I}^{C u, W} .
$$

The substrate-interaction contribution originates from the superposition of intrinsic growth stresses (due to the MS deposition process) and thermal stresses (originating from the thermal expansion mismatch). Film growth by lowtemperature PVD methods generally proceeds by an islandgrowth mode, which results in the accumulation of compressive stresses after (closed) film formation (as also observed in the present study): see Refs. 40-45,54. Moreover, when high-energetic species (backscattered neutrals, sputtered atoms or accelerated ions) are involved, as is the case in the applied MS process, additional compressive stresses can be generated due to the incorporation of defects and impurities. ${ }^{46}$ Moreover, other kinds of defects like atomic mixing in the nanometer scale at the $\mathrm{Cu} / \mathrm{W}$ interface can also be present $^{47}$ (see supplementary material). These compressive 
stress contributions are related to the growth (deposition) process and thus add to the growth stress contribution in Eq. (1). In addition, large coherency stresses (several GPa) may arise at solid-solid interfaces due to the lattice mismatch between the two sub-lattices, which may partially relax by the introduction of misfit dislocations above a certain critical thickness. ${ }^{44,48}$ For the $\mathrm{Cu} / \mathrm{W}$ NML under study, the coherency stress in the alternating $\mathrm{Cu}$ and $\mathrm{W}$ nanolayers (of the same thickness) induces equal and opposite forces into the layer, i.e.,

$$
\left\langle\sigma_{c o h}^{C u}\right\rangle=-\left\langle\sigma_{c o h}^{W}\right\rangle .
$$

This yields to the following expression for the total average stress:

$$
\left\langle\sigma_{T O T}\right\rangle=2 \sigma_{S I}^{C u, W} .
$$

By employing Eqs. (1)-(3), the coherency stress in the constituent layers can be derived from the measured total average in plane stress. In Fig. 7, the thus obtained values for $\sigma_{c o h}$ for $\mathrm{Cu}$ and $\mathrm{W}$ are plotted as a function of the annealing temperature. A comparison of the values for the total stress and the coherency stress in $\mathrm{W}$ and $\mathrm{Cu}$ (i.e., compare Figs. 6 and 7 , respectively) indicates that the $\sigma_{c o h}$ is significantly smaller than the total stress and, consequently, $\sigma_{S I}$ is the dominant contribution to the total stress. Again assuming that the $\mathrm{W}$ nanolayers superimpose their stress on $\mathrm{Cu}$ and considering the relatively small thermal mismatch between $\mathrm{W}, \mathrm{Si}$, and sapphire (see above), it follows that $\sigma_{S I}$ is dominated by the growth stress contribution (see Eq. (1)). Coherency stresses in the individual layers are thought to facilitate the degradation process, thereby lowering the effective activation temperature. ${ }^{31,49}$ In our findings, the contribution from coherency stresses is found to be smaller than that from growth stress and also similar on Si and sapphire substrates, in accordance with the experimental observation that NML degradation occurs within the same temperature range for the different substrates considered.

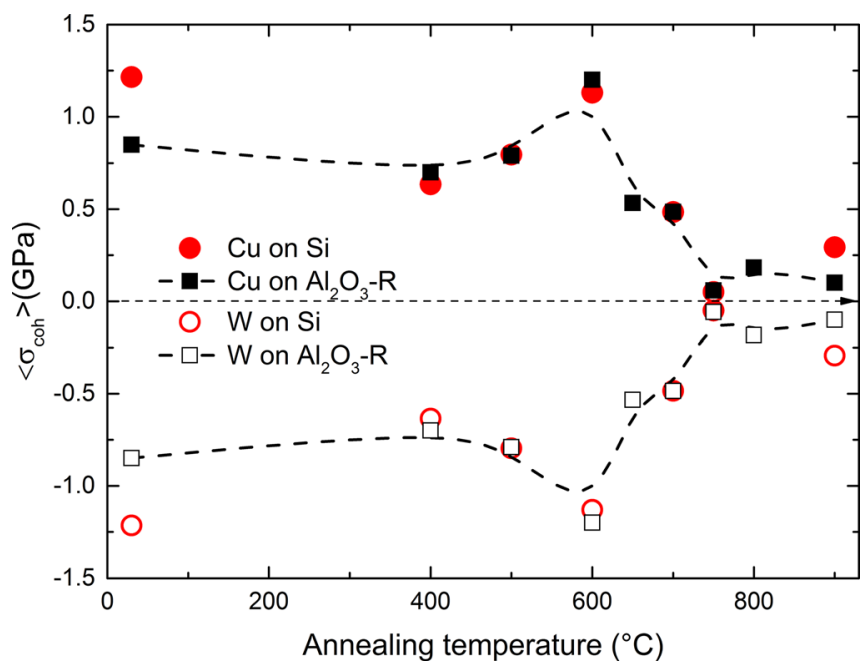

FIG. 7. Average coherency stress evolution for $\mathrm{W}$ and $\mathrm{Cu}$ sublayers grown on $\mathrm{Si}$ and $\mathrm{Al}_{2} \mathrm{O}_{3}-\mathrm{R}$ substrates. The lines are guides to the eye.
Finally, it is remarked that the conditions of the magnetron sputter process can be exploited to tailor the sputterdeposited microstructure (e.g., grain size, thickness, dislocation density, and point defects) and thereby the residual growth stress level..$^{50-56}$ Different growth stress levels in the $\mathrm{Cu} / \mathrm{W}$ NMLs may shift the thermal activation and rate kinetics of the NML degradation process, which would open new routes for microstructural engineering of NML systems for a broad range of applications.

\section{CONCLUSIONS}

The impact of thermal treatment on the stress state and evolving microstructure of $\mathrm{Cu} / \mathrm{W}$ nano-multilayers, as deposited on different substrates by magnetron sputtering, was investigated by in-situ high temperature XRD (HTXRD) and high resolution SEM. The alternating $\mathrm{Cu}$ and $\mathrm{W}$ nanolayers grow along the preferred directions of [111] for $\mathrm{Cu}$ and $[110]$ for $\mathrm{W}$, which results in an out-of-plane orientation relationship according to $\mathrm{Cu}\{111\} \|\{110\}$, independently of the substrate. The $\mathrm{Cu} / \mathrm{W} \mathrm{NML}$ on $\mathrm{Al}_{2} \mathrm{O}_{3}-\mathrm{C}$ and $\mathrm{Al}_{2} \mathrm{O}_{3}$ - $\mathrm{R}$ substrates also develops an in-plane texture according to $\mathrm{Cu}\{111\}\langle 10 \overline{1}\rangle|| \mathrm{W}\{110\}\langle 00 \overline{1}\rangle$, as inherited from the epitaxy between the first $\mathrm{W}$ buffer layer and the singlecrystalline $\mathrm{Al}_{2} \mathrm{O}_{3}$ substrate. Such an in-plane texture is absent for the $\mathrm{Cu} / \mathrm{W}$ NMLs on the $\mathrm{Si}(001)$ substrate, because the amorphous $\mathrm{Si}_{3} \mathrm{~N}_{4}$ interlayer prevents epitaxial growth of the first $\mathrm{W}$ buffer layer. The diffracted intensity modulation (i.e., satellite structure), typical of a periodically ordered NML structure, vanishes completely during heating in the temperature range of $750-900^{\circ} \mathrm{C}$, independent of the substrate. The disappearance of the satellite structure coincides with the appearance of the $\mathrm{Cu}(200)$ reflection (using surface sensitive GI-XRD), as attributed to the thermally activated and stress-assisted outflow of confined $\mathrm{Cu}$ from the interior of the NML to the outer surface. The NML degradation process is accompanied by abrupt grain coarsening of $\mathrm{W}$ in the range of $750-900^{\circ} \mathrm{C}$. The resulting $\mathrm{W}$ grain size remains nearly constant during subsequent cooling down to RT.

XRD stress analysis indicates that the stress state of the $\mathrm{Cu}$ nanolayers during deposition and upon heating is largely imposed by the accumulated stresses in the much stiffer $\mathrm{W}$ nanolayers. As result, the measured course of the stress evolution of $\mathrm{Cu}$ with annealing temperature is qualitatively similar for $\mathrm{Cu}$ and $\mathrm{W}$. The as-deposited $\mathrm{Cu}$ nanolayers possess an average in-plane compressive stress of $-1.5 \mathrm{GPa}$ at $\mathrm{RT}$, which is fully released after the annealing at $500^{\circ} \mathrm{C}$ which coincides with the temperature where $\mathrm{Cu}$ outflow is detected on the surface. The $\mathrm{W}$ nanolayers exhibit a significantly larger in-plane compressive stress of $-3.5 \mathrm{GPa}$ at $\mathrm{RT}$, which is only partially released after the annealing at $500^{\circ} \mathrm{C}$. Fast relaxation of compressive stresses in the $\mathrm{W}$ nanolayers only occurs upon degradation of the NML structure in the range of $750-900^{\circ} \mathrm{C}$, as accompanied by grain coarsening. The existence of high compressive stresses in the $\mathrm{Cu}$ and $\mathrm{W}$ nanolayers in the as-deposited state was found to originate mainly from growth stresses generated during the deposition process: i.e., the contribution of coherency stress in the $\mathrm{Cu}$ and $\mathrm{W}$ nanolayers on the total stress state is relatively small. 
This study shed light on the role of stress in multicomposite, nano-multilayered materials subjected to thermal treatments. This work can be considered as the basis for further investigations on the effect of, e.g., layer thickness, layer sequence and deposition parameters on the microstructure, stress state, and thermal stability of $\mathrm{Cu} / \mathrm{W}$ NML systems.

\section{SUPPLEMENTARY MATERIAL}

See supplementary material for the XRD geometries, stress data analysis in $\mathrm{Cu}$ and $\mathrm{W}$ layers, and the comparison of the $\sin ^{2} \psi$ method with the CGM for $\mathrm{W}$ layers.

\section{ACKNOWLEDGMENTS}

The authors are grateful to Dr. D. Ariosa and Dr. T. Ivas for valuable discussions, Dr. G. Pigozzi for performing preliminary experiments, and Dr. D. Passerone for theoretical support. The Empa laboratory for reliability science and technology is acknowledged for the provision of the scanning electron microscope facilities.

${ }^{1}$ M. Stueber, H. Holleck, H. Leiste, K. Seemann, S. Ulrich, and C. Ziebert, "Concepts for the design of advanced nanoscale PVD multilayer protective thin films," J. Alloys Compd. 483, 321-333 (2009).

${ }^{2}$ T. W. Barbee, "Interfacial effects in multilayers," MRS Proc. 524, 145 (1998).

${ }^{3}$ Y. P. Perelygin, A. E. Rosen, I. S. Los', and S. Y. Kireev, "A new corrosion-resistant multilayer material," Prot. Met. Phys. Chem. Surf. 50, 856-859 (2014).

${ }^{4}$ B. Clemens, H. Kung, and S. Barnett, "Structure and strength of multilayers," MRS Bull. 24, 20-26 (1999).

${ }^{5}$ O. Knotek, F. Lffler, and G. Krmer, "Process and advantage of multicomponent and multilayer PVD coatings," Surf. Coat. Technol. 59, 14-20 (1993).

${ }^{6}$ S. J. Lloyd and J. M. Molina-Aldareguia, "Multilayered materials: A palette for the materials artist," Philos. Trans. R. Soc., A 361, 2931-2949 (2003).

${ }^{7}$ G. Abadias, A. Michel, C. Tromas, C. Jaouen, and S. Dub, "Stress, interfacial effects and mechanical properties of nanoscale multilayered coatings," Surf. Coat. Technol. 202, 844-853 (2007).

${ }^{8}$ S. K. Shrama, N. Saurakhiya, S. Barthwal, R. Kumar, and A. Sharma, "Tuning of structural, optical, and magnetic properties of ultrathin and thin $\mathrm{ZnO}$ nanowire arrays for nano device applications," Nanoscale Res. Lett. 9, 122 (2014).

${ }^{9}$ C. P. Kuo, S. K. Vong, R. M. Cohen, and G. B. Stringfellow, "Effect of mismatch strain on band gap in III-V semiconductors," J. Appl. Phys. 57, 5428-5432 (1985).

${ }^{10}$ J. A. Ruud, A. Witvrouw, and F. Spaepen, "Bulk and interface stresses in silvernickel multilayered thin films," J. Appl. Phys. 74, 2517-2523 (1993).

${ }^{11}$ R. Treml, D. Kozic, J. Zechner, X. Maeder, B. Sartory, H.-P. Gänser, R. Schöngrundner, J. Michler, R. Brunner, and D. Kiener, "High resolution determination of local residual stress gradients in single- and multilayer thin film systems," Acta Mater. 103, 616-623 (2016).

${ }^{12}$ B. Girault, P. Villain, E. L. Bourhis, P. Goudeau, and P.-O. Renault, "X-ray diffraction analysis of the structure and residual stresses of W/Cu multilayers," Surf. Coat. Technol. 201, 4372-4376 (2006).

${ }^{13}$ B. Girault, D. Eyidi, T. Chauveau, D. Babonneau, P.-O. Renault, E. Le Bourhis, and P. Goudeau, "Copper coverage effect on tungsten crystallites texture development in W/Cu nanocomposite thin films," J. Appl. Phys. 109, 014305 (2011).

${ }^{14}$ M. Monclús, M. Karlik, M. Callisti, E. Frutos, J. LLorca, T. Polcar, and J. Molina-Aldareguía, "Microstructure and mechanical properties of physical vapor deposited $\mathrm{Cu} / \mathrm{W}$ nanoscale multilayers: Influence of layer thickness and temperature," Thin Solid Films 571(Part 2), 275-282 (2014).

${ }^{15}$ A. Miedema, "On the heat of formation of solid alloys," J. Less Common Metals 41, 283 (1975).

${ }^{16}$ F. Moszner, C. Cancellieri, M. Chiodi, S. Yoon, D. Ariosa, J. JanczakRusch, and L. Jeurgens, "Thermal stability of $\mathrm{Cu} / \mathrm{W}$ nano-multilayers," Acta Mater. 107, 345-353 (2016).
${ }^{17}$ P. Goudeau, K. F. Badawi, A. Naudon, and G. Gladyszewski, "Determination of the residual stress tensor in $\mathrm{Cu} / \mathrm{W}$ multilayers by xray diffraction," Appl. Phys. Lett. 62, 246-248 (1993).

${ }^{18}$ S. Wen, R. Zong, F. Zeng, Y. Gao, and F. Pan, "Evaluating modulus and hardness enhancement in evaporated $\mathrm{Cu} / \mathrm{W}$ multilayers," Acta Mater. 55, 345-351 (2007).

${ }^{19}$ P. Goudeau, K. Badawi, A. Naudon, and N. Durand, "Residual stress and microstructure of Cu/W multilayers," MRS Proc. 308, 713 (1993).

${ }^{20}$ P. Villain, D. Faurie, P.-O. Renault, E. L. Bourhis, P. Goudeau, and K.-F. Badawi, "Mechanical properties and size effect in nanometric W/Cu multilayers,” MRS Proc. 875, O1.3 (2005).

${ }^{21}$ P. Villain, P. Goudeau, F. Badawi, G. Ouyang, G. W. Yang, and V. Pélosin, "Physical origin of spontaneous interfacial alloying in immiscible W/Cu multilayers," J. Mater. Sci. 42, 7446-7450 (2007).

${ }^{22}$ W. M. Yim and R. J. Paff, "Thermal expansion of AlN, sapphire, and silicon,” J. Appl. Phys. 45, 1456-1457 (1974).

${ }^{23}$ D. Lide, CRC Handbook of Chemistry and Physics, 85th ed. (Taylor \& Francis, 2004), Vol. 85.

${ }^{24}$ B. D. Cullity, Elements of X-Ray Diffraction, 2nd ed. (Addison-Wesley Pub. Co., Boston, 1956)

${ }^{25}$ U. Welzel, J. Ligot, P. Lamparter, A. C. Vermeulen, and E. J. Mittemeijer, "Stress analysis of polycrystalline thin films and surface regions by X-ray diffraction,” J. Appl. Crystallogr. 38, 1-29 (2005).

${ }^{26}$ P. Klimanek, "I. C. Noyan, J. B. Cohen. Residual stress measurement by diffraction and interpretation. Springer series on Materials Research and Engineering, edited by B. Ilschner and N. J. Grant. Springer-Verlag, New York-Berlin-Heidelberg-London-Paris-Tokyo 1987, 276 Seiten, 160 Bilder, 31 Tabellen, DM 138., ISBN 3-540-96378-2," Cryst. Res. Technol. 24, K37 (1989).

${ }^{27}$ B. Clemens and J. Bain, "Stress determination in textured thin films using X-ray diffraction," MRS Bull. 17, 46-51 (1992).

${ }^{28}$ A. Miller, H. M. Manasevit, D. H. Forbes, and I. B. Cadoff, "Orientation relationships in the heteroepitaxial tungsten-on-sapphire system," J. Appl. Phys. 37, 2921-2922 (1966).

${ }^{29}$ J. H. Souk, A. Segmller, and J. Angilello, "Oriented growth of ultrathin tungsten films on sapphire substrates,” J. Appl. Phys. 62, 509-512 (1987).

${ }^{30}$ B. M. Clemens and J. G. Gay, "Effect of layer-thickness fluctuations on superlattice diffraction,” Phys. Rev. B 35, 9337-9340 (1987).

${ }^{31}$ M. Bobeth, W. Pompe, and A. Ullrich, "Destratification mechanisms in coherent multilayers," J. Metastable Nanocryst. Mater. 19, 153 (2004).

${ }^{32}$ A. J. Asaro and W. A. Tiller, "Diffusion and interface control of reactions in alloys," Metall. Trans. 3, 1789 (1972).

${ }^{33}$ C. P. Liang, J. L. Fan, H. R. Gong, X. Liao, X. Zhu, and S. Peng, "Interface structure and work function of W-Cu interfaces," Appl. Phys. Lett. 103, 211604 (2013).

${ }^{34}$ K. Reshöft, C. Jensen, and U. Köhler, "Atomistics of the epitaxial growth of Cu on W(110)," Surf. Sci. 421, 320-336 (1999).

${ }^{35}$ E. Z. Luo, Q. Cai, W. F. Chung, B. G. Orr, and M. S. Altman, "Competing desorption pathways during epitaxial growth: Leem investigation of $\mathrm{Cu}$ / W(110) heteroepitaxy," Phys. Rev. B 54, 14673-14678 (1996).

${ }^{36}$ R. Raghavan, J. Wheeler, D. E. de los Ojos, K. Thomas, E. Almandoz, G. Fuentes, and J. Michler, "Mechanical behavior of $\mathrm{Cu} / \mathrm{TiN}$ multilayers at ambient and elevated temperatures: Stress-assisted diffusion of $\mathrm{Cu}$," Mater. Sci. Eng., A 620, 375-382 (2015).

${ }^{37}$ W. C. Overton and J. Gaffney, "Temperature variation of the elastic constants of cubic elements. I. Copper,” Phys. Rev. 98, 969-977 (1955).

${ }^{38}$ F. H. Featherston and J. R. Neighbours, "Elastic constants of tantalum, tungsten, and molybdenum," Phys. Rev. 130, 1324-1333 (1963).

${ }^{39}$ J. A. Bain, L. J. Chyung, S. Brennan, and B. M. Clemens, "Elastic strains and coherency stresses in Mo/Ni multilayers," Phys. Rev. B 44, 1184-1192 (1991).

${ }^{40}$ D. M. Mattox, "Atomistic film growth and some growth-related film properties," in Handbook of Physical Vapor Deposition (PVD) Processing, 2nd ed., edited by D. M. Mattox (William Andrew Publishing, Boston, 2010), Chap. 10, pp. 333-398.

${ }^{41}$ I. Petrov, P. B. Barna, L. Hultman, and J. E. Greene, "Microstructural evolution during film growth," J. Vac. Sci. Technol., A 21, S117-S128 (2003).

${ }^{42}$ J. A. Floro, S. J. Hearne, J. A. Hunter, P. Kotula, E. Chason, S. C. Seel, and C. V. Thompson, "The dynamic competition between stress generation and relaxation mechanisms during coalescence of Volmer-Weber thin films," J. Appl. Phys. 89, 4886-4897 (2001). 
${ }^{43}$ A. L. Shull and F. Spaepen, "Measurements of stress during vapor deposition of copper and silver thin films and multilayers," J. Appl. Phys. 80, 6243-6256 (1996).

${ }^{44}$ P. Politi, G. Grenet, A. Marty, A. Ponchet, and J. Villain, "Instabilities in crystal growth by atomic or molecular beams," Phys. Rep. 324, 271-404 (2000).

${ }^{45}$ D. Flötotto, Z. M. Wang, L. P. H. Jeurgens, and E. J. Mittemeijer, "Kinetics and magnitude of the reversible stress evolution during polycrystalline film growth interruptions," J. Appl. Phys. 118, 055305 (2015).

${ }^{46}$ R. Koch, "Stress in evaporated and sputtered thin films a comparison," Surf. Coat. Technol. 204, 1973-1982 (2010).

${ }^{47}$ P. Goudeau, P. Villain, T. Girardeau, P.-O. Renault, and K.-F. Badawi, "Elastic constants investigation by x-ray diffraction of in situ deformed metallic multi-layers," Scr. Mater. 50, 723-727 (2004).

${ }^{48}$ F. Reichel, L. P. H. Jeurgens, and E. J. Mittemeijer, "Thermodynamic model of oxide overgrowth on bare metals: Relaxation of growth strain by plastic deformation," Phys. Rev. B 74, 144103 (2006).

${ }^{49}$ B. J. Daniels, W. D. Nix, and B. M. Clemens, "Effect of coherency stresses on the hardness of epitaxial $\mathrm{Fe}(001) / \mathrm{Pt}(001)$ multilayers," Appl. Phys. Lett. 66, 2969-2971 (1995).
${ }^{50} \mathrm{C}$. Thompson, "The yield stress of polycrystalline thin films," J. Mater. Res. 8, 237-238 (1993).

${ }^{51}$ O. Auciello, S. Chevacharoenkul, M. S. Ameen, and J. Duarte, "Controlled ion beam sputter deposition of W/Cu/W layered films for microelectronic applications," J. Vac. Sci. Technol., A 9, 625-631 (1991).

${ }^{52}$ F. Spaepen, "Interfaces and stresses in thin films," Acta Mater. 48, 31-42 (2000).

${ }^{53}$ O. Thomas, P. Gergaud, S. Labat, L. Barrallier, A. Charai, C. Alfonso, B. Gilles, and A. Marty, "Residual stresses in metallic multilayers," J. Phys. IV 6, 125-134 (1996).

${ }^{54}$ E. Chason, B. W. Sheldon, L. B. Freund, J. A. Floro, and S. J. Hearne, "Origin of compressive residual stress in polycrystalline thin films," Phys. Rev. Lett. 88, 156103 (2002).

${ }^{55}$ R. C. Cammarata, T. M. Trimble, and D. J. Srolovitz, "Surface stress model for intrinsic stresses in thin films," J. Mater. Res. 15, 2468-2474 (2000).

${ }^{56} \mathrm{R}$. Koch, "The intrinsic stress of polycrystalline and epitaxial thin metal films," J. Phys.: Condens. Matter 6, 9519 (1994). 